\title{
Identidad cultural. La película etnográfica en Serbia ${ }^{1}$
}

Dragana Radojičić*

Resumen: La película etnográfica representa un subtipo de película documental, uno que trata de la vida y las tradiciones populares, que puede ser usado como ilustración, pero también como fuente de la investigación etnográfica y antropológica. La película etnológica, así como se hace hoy en Serbia, puede ser utilizada como fuente para el estudio de la identificación cultural, pero también como instrumento para establecer la identidad cultural. Cuatro películas domésticas que unen lo tradicional y lo moderno serán analizadas a nivel de la temática material y espiritual.

Palabras clave: estado de situación actual - Festival Internacional de la Película Etnográfica en Belgrado - identidad cultural - medios de comunicación - película etnográfica.

[Resúmenes en inglés y portugués en la página 225]

${ }^{*}$ Se licenció, realizó la maestría y, asímismo, el doctorado en el departamento de etnología de la Facultad de Filosofía de Belgrado (Serbia). Directora del Instituto Etnográfico de la Academia Serbia de Ciencias y Artes.

\section{Introducción}

Mi devoción por la antropología visual proviene de un largo trabajo en la organización del Festival Internacional de la Película Etnológica en Belgrado.

La cultura es una fuente de futuras oportunidades, no sólo una herencia del pasado sino un reto que exige cambios. El cambio social acelerado, la información difundida, la uniformidad cultural y los medios de comunicación masiva traen unos valores y categorías culturales nuevos que afectarán al hombre común, un hombre de nueva época que vive la vida como en una película. El incontrolable río del tiempo es una fuerza irrefrenable que nos somete a su curso; cambia el mundo que nos rodea y provoca efimeridad.

Los investigadores del pasado manifiestan el tiempo por medio del uso de los modelos antropológicos y etnológicos para mostrar el desarrollo de la cultura tradicional en una serie de fases que cambian de manera significativa de una situación a otra, causando así la apariencia de la época pasada. La etnología y la antropología se caracterizan por poseer muchas teorías, métodos y metodologías que están directa e/o indirectamente asociados a la interpretación de la antropología visual. Tales teorías surgieron cuando fue levantada la 
cortina que, por un lado separaba a los espectadores del espectáculo de marionetas, y por otro la misteriosa pantalla de cine y televisión del espectador estático. Había sido creada una frontera entre ellos y el mundo que estaban viendo en el proceso de la "inmersión" del universo global. Las primeras premisas básicas de la cinematografía surgieron en la primera proyección pública de una película en el Grand Café en París, cuando la escena de un tren que venía asustó a los espectadores. No obstante, los "embriones" de la película habían surgido antes de la aparición de la película como un arte, la más joven entre las formas de la expresión artística que datan de siglos atrás (Radojičić, 2010: 628).

Los primeros cineastas al principio creían que una cámara era un instrumento ideal para grabar imágenes de la realidad sin mayor actividad humana. La comprensión de la película como un lenguaje, un medio de comunicación y un recurso para orientar a la gente y formar su opinión vino más tarde, y junto con esto vino la necesidad de estudios, sistematización e instrucción en técnicas de comunicación (Kriznar, 2007: 9).

En vista de lo mencionado arriba, la etnología como ciencia empírica de la cultura a lo mejor no se puede "retirar" del nivel actual del desarrollo cultural a un lugar aparentemente más seguro, del cual podrá surtir un efecto aplacable en la cultura. La etnología se tiene que enfrentar a las innovaciones en la cultura, sin dejarse cegar por ellas (Bausinger, 2002: 320).

El hecho es que la cultura de los medios de comunicación es muy importante como una esfera significante del mundo moderno y las preguntas cruciales para los etnólogos son: ¿Cómo están integrados los medios de comunicación en la vida cotidiana y de qué manera modelan y estructuran la vida de la gente? (Bausinger, 2002: 318).

La película como el medio de comunicación masiva más influyente, tiene una importancia especial para la etnología y la antropología. Esto se nota sobre todo en el uso de los métodos del trabajo y la presentación del fenómeno documental en el campo etnológico, que a su vez impone la pregunta sobre el conocimiento y la creatividad de los etnólogos. La película crece en el tiempo y en el espacio abarcando así muchos temas y dándoles la oportunidad a esos temas que se extiendan. Esto llama nuestra atención, pero no debería forzarnos a que nos centremos en ningún fenómeno en particular.

Los países europeos y no europeos han estado trabajando por décadas en las películas etnográficas que tratan acerca de acontecimientos que el proceso histórico intenta de "vencer" y cuyo recuerdo se transmitirá de manera oral o a través de la descripción escrita, en el mejor de los casos. Al mismo tiempo las películas etnográficas proporcionan el material documental sin precedentes/incomparable para los investigadores.

Jean Dominique Lajoux considera que la película se está convirtiendo en el medio dominante de la expresión y muchos antropólogos la utilizan como un nuevo instrumento de presentación de su investigación (Chiozzi, 1989: 34-39).

La "película etnográfica" como subtipo de la película documental se puede usar en la investigación etnográfica y antropológica, puesto que documenta la vida popular y las costumbres. Existen dos principales subtipos de película etnológica considerando el fenómeno de la documentación: una única o repetida grabación de un acontecimiento autentico y 'la modelación del tema' -entre la grabación y la superestructura, la elaboración dramatúrgica y la reconstrucción. Las cuestiones importantes relacionadas con este asunto son la selección de temas, el enfoque y la realización, la elección entre reconstrucción y estili- 
zación y la elección del escenario. Todos estos aspectos combinados crean una observación completa utilizando la duración, las imágenes, el texto y la música.

Uno de los primeros fundadores de la antropología visual F. Boas puede ser considerado por lo menos en parte responsable del hecho de que la película se haya convertido en la parte fundamental de la experiencia y trabajo de los etnólogos en este campo. Las secuencias que Boas filmó no eran más que datos visuales útiles para la investigación visual: "Es un proceso que impactará a los puristas, pero yo lo considero perfectamente apropiado en determinadas circunstancias"(Chiozzi, 1989: 56). Boas de hecho era un experto en la teoría cultural, lo que le permitió que tomara algunos elementos del comportamiento y los separara del contexto con el fin de documentarlos y analizarlos. Él quería captar con su cámara diferentes conductas y movimientos del cuerpo porque consideraba que estos eran elementos de la cultura. Boas creía que cualquier actividad humana era una realidad cultural y por lo tanto el tema de los estudios antropológicos y etnológicos. El profesor P. Chiozzi explicó esto en su estudio Reflexiones sobre la película etnográfica con la bibliografía general, que fue publicado a finales de los ochenta en la célebre revista Antropología Visual (Chiozzi, 1989: 56).

\section{Desarrollo de la antropología visual en Serbia}

El trabajo que desarrolló el centro visual en el Museo Etnográfico de Belgrado ha recorrido un largo camino desde el comienzo del trabajo organizado en la antropología visual y sus principios asumidos hasta la fase contemporánea en curso. Han sido perfilados nuevos métodos de trabajo, cuestiones no elaboradas, organización de las materias universitarias, elaboración científica, definición del perfil del público que tanto regular como ocasionalmente ve las películas etnográficas y el concepto y continuo trabajo del Festival Internacional de la Película Etnológica. Estas actividades se continuarán dentro del marco de una exhaustiva creación etnológica y antropológica visual (Radojičić, 2010: 629-630).

Está claro que el interés de los creadores de varios tipos de procedimientos educativos y artísticos oculta cierto peligro. Este peligro no proviene sólo de la amplitud de la materia de nuestra ciencia, sino también de la convicción (no siempre cierta) de que es relativamente fácil tratar los temas etnológicos debido a su familiaridad y una relativa claridad (Drljača, 2003: 7).

Ha resultado que el contenido etnográfico es importante para la película documental y la película en general, mientras que sus autores y temas han resultado ser importantes para la antropología. Además de su uso como un medio que sirve para documentar auténticos hechos culturales y como un recurso de estudio de acciones y comportamiento característicos para miembros de cierta comunidad, la película se ha convertido en un factor importante del cambio cultural. Como tal, la película ha evolucionado hasta convertirse en un hecho antropológico que merece ser investigado por separado (Jovanović, 2005: 13). El documental serbio más antiguo que ha sido conservado, La Coronación del Rey Pedro I Karađorđević, fue grabada en la ocasión de la ceremonia de coronación en Belgrado en 1904 gracias a Arnold Moore Wilson, el cónsul honorario de Serbia en Sheffield (Reino Unido), y su camarógrafo. Con su cámara lograron documentar la apariencia de la capital 
serbia, la procesión de coronación, el mercado de Kraljevo, los monasterios Žiča i Studenica, las ciudades de Serbia así como la vida y la ropa de la gente. Esta película hoy representa un documento etnológico invaluable.

Podemos decir lo mismo para las películas La boda en Topola y La boda en Galičnik del año 1934. Estas películas, al igual que las secuencias del pueblo Slanci cerca de Belgrado, se han conservado gracias al archivo de la Cinemateca Serbia (Marjanović, 2002: 274, 275). El centésimo aniversario del rodaje de la primera película en Serbia se celebró en 2011. En el año 1911 se fundó La Asociación de Grabación de las Películas Populares Serbias. Los fundadores eran el industrial y el propietario del primer cine permanente en Serbia Svetozar Botorić, el ilustre actor de teatro, director y bon vivant Ilija Stanojević, y el camarógrafo de la compañía de producción de películas más famosa de Europa -The Pate Brothers- Louis de Berry (nombre verdadero - Lajoš Zoltan Arpad Pitrolf). La Cinemateca Yugoslava, como el archivo de las películas nacionales de la República de Serbia, en 2003 logró encontrar las películas de Botorić en el Archivo de Películas de Viena, que se creían perdidas. Han sido restauradas y se han sacado unas copias de ellas, así que hoy podemos verlas en DVD. De la Colección de Svetozar Botorić, Tomo 2, a los etnólogos y antropólogos les interesará particularmente la película Una boda pueblerina serbia, grabada en 1911 en un pueblo cerca de la ciudad de Kruševac.

La primera asamblea de la película etnográfica y folclórica de los países balcánicos se celebró en 1964 en la ciudad de Niš; en 1992 se fundó el Festival de la Película Etnológica. El primer festival fue organizado en el monasterio Prohor Pčinjski, donde se celebró hasta el año 1998, luego del cual fue trasladado al Museo Etnográfico de Belgrado.

Los festivales organizados por el Museo Etnográfico de Belgrado han tenido un papel importante en el desarrollo de la etnología/antropología en Serbia. En las primeras décadas del siglo XX los colaboradores del museo reconocieron la mágica importancia de las imágenes móviles, y el conservador Petar Z. Petrović grabó un interesante ritual tradicional para las necesidades del museo. Esta película, al igual que muchas más, hoy se conserva en los archivos y representa un documento histórico inapreciable. Sin embargo, las actividades más significativas tuvieron lugar en las últimas décadas del siglo XX, incluyendo el trabajo y los esfuerzos importantes de Ljubomir Reljić. Como conservador del Museo Etnográfico de Belgrado, Reljić ha producido desde 1960, en colaboración con la televisión nacional serbia, una serie de películas etnológicas importantes. Muchos de los colaboradores del Museo han contribuido significativamente al desarrollo del pensamiento/idea visual en la etnología o antropología, incluyendo a Petar Kostić, Sofija Kostić, Vesna Marjanović, Velibor Stojaković, Marko Stojanović, Saša Srećković y Ranko Barišić y otros que han aportado considerables esfuerzos y dedicación en el campo de la antropología visual.

Los premios y la reputación del Festival, que este año será organizado por vigésima primera vez en el Museo Etnográfico de Belgrado, han contribuido mucho a que se convirtiera en un evento prestigioso no sólo en Serbia, sino también en la región. El número de películas hechas exclusivamente para el festival -sobre todo por amateurs- sigue creciendo cada año. El Festival influyó en la existencia de muchos llamados mini-festivales y, por consiguiente, ellos y las películas que han traído, han inspirado a los amateurs a hacer sus propios trabajos de audio y video, muchos de los cuales se han vuelto luego muy populares (Radojičić, 2010: 625). 
Una de las tareas importantes del Festival es promover nuevos enfoques creativos y enfoques de investigación en la película documental antropológica y seguir los últimos cambios, tendencias y desarrollo cultural. El objetivo del Festival es promover la cultura tradicional por todo el mundo en una época cuando la globalización nos impone la unificación de las pautas culturales.

Cuando se trata de la participación de los etnólogos y antropólogos serbios en la creación de las películas etnológicas, deberíamos mencionar que hasta hoy un 30\% de los que trabajan en varias instituciones ha colaborado en la producción de la película etnológica: $60 \%$ de ellos han sido colaboradores y conservadores del museo, $25 \%$ colaboradores del Instituto, 15\% colaboradores de la Facultad de filosofía y 5\% de ellos han sido etnólogos, o colaboradores de varios medios de comunicación. Después de examinar el archivo del Museo, V. Marjanović llegó a la conclusión de que se podían distinguir varios tipos de participación de los etnólogos domésticos -los que han trabajado en la película etnológica hasta el presente: $60 \%$ han sido asesores expertos, $25 \%$ escritores del guion y $15 \%$ camarógrafos, dependiendo del tema. La película etnológica tiene las características siguientes al mismo tiempo: es un documento en tiempo y espacio, una reconstrucción del pasado y un documento sobre un evento auténtico (Marjanović, 2002: 280-285).

En su archivo de películas, el Museo Etnográfico de Belgrado, guarda gran número de cintas de video y DVD con más de 500 títulos. La gran mayoría son películas domesticas obtenidas a través de los festivales de película etnológica y a través de los amigos y conocidos, mientras que las películas extranjeras se han obtenido a través de los festivales. Estas películas con mayor frecuencia trataban acerca de las costumbres y tradiciones y hay también unas reconstrucciones más o menos exitosas. Se pueden distinguir dos categorías de autores de estas películas: profesionales (expertos en cine y televisión, etnólogos, etnomusicólogos) y amateurs (la gente de las comunidades locales que graba las costumbres y tradiciones).

\section{El análisis}

Cada vez hay más películas que tratan sus respectivos temas a un nivel fenomenológico e intentan documentar un evento real, sin idealizar la comunidad en la que ahondan. Los autores logran evitar la idealización, a no ser que traten de reconstruir costumbres y tradiciones. Esto es consecuencia de su trabajo en base a documentos etnográficos anteriores durante la investigación que no distinguía el ideal del nivel auténtico del modelo.

Las películas etnológicas producidas en Serbia hoy se pueden usar como una fuente para analizar la identificación cultural. Hoy en día la representación visual de la herencia cultural es una fuente irreemplazable para muchas ciencias sociales, no sólo para etnología y antropología. Tiene cada vez mayor importancia en el proceso de educación y en la presentación de la herencia cultural en los medios de comunicación masiva.

Ha sido difícil elegir las películas que serán analizadas en este trabajo, entre todas las que he visto en mis 20 años de investigación en antropología visual en Serbia. Estas películas deben subrayar efectivamente ciertos elementos específicos de la cultura espiritual, social y material que representarían una imagen explícita de la identidad en varias zonas geo- 
gráficas de Serbia. Ellas también reflejan la necesidad de conservar la identidad cultural y, entre otras cosas, son una buena fuente de documentos etnográficos de Serbia y por esa razón se presentan en este estudio.

Consideré lógico comenzar con el análisis de los logros de las películas amateurs, lo que ayudaría, junto con el análisis de la reconstrucción y de dos películas modernas urbanas, a ilustrar la relación entre lo tradicional y lo contemporáneo en la sociedad serbia.

Este estudio analiza el contenido de siguientes películas etnográficas:

Los logros de Dobrivoje Pantelić y su esposa Dobrila del pueblo de Radjevina, quienes han ganado muchos premios en este festival, al igual que en los festivales de Kučevo y Omoljica, que tienen gran importancia. Este par de trabajadores dedicaron todo su tiempo libre a montar una pequeña tienda familiar donde producen películas etnológicas. Su contribución a la grabación, de una manera original, de los patrones todavía existentes de la conducta tradicional en Loznica y sus alrededores es inmensa.

Radjevina entre los Perales, dirigida por Dobrivoje y Dobrila Pantelić, Serbia (2007).

Este documental amateur describe el sistema de valores en el que se basan las relaciones socialmente aceptables entre géneros en la cultura tradicional en el pueblo de Radjevina (noroeste de Serbia). Esta extraordinaria realización de los productores amateurs no es sólo un intento de crear tal película, sino que además representa la transmisión de los productos culturales de una situación de la vida (igualdad de género presentada a través del modelo tradicional) a un contexto diferente situado en la actualidad. También representa todos los aspectos y características de una forma tradicional de la vida en el ámbito rural. Las reconstrucciones de las películas, en el sentido cognitivo, generalmente tratan de 'lo que está ausente' y sólo parcialmente de la forma contemporánea del fenómeno. En estas películas el evento actual no es más que una directriz alrededor de la cual se teje el contenido reconstruido, añadido. "Archivar las reconstrucciones es una tarea compleja desde el punto de vista de la investigación y organización, que no se puede concebir sin una enorme experiencia previa en este campo" (Drljača 2003: 19).

A diferencia de la canción o baile, que no han sido sometidos a las limitaciones en el pasado, las costumbres y su desempeño se han perdido a lo largo del tiempo o debido a la prohibición.

En Serbia, debido a la discontinuidad o a las circunstancias históricas, es especialmente difícil reconstruir los temas medievales o temas de un pasado lejano. Deberíamos usar la reconstrucción 'cuando el fenómeno que queremos reconstruir ya no existe en su forma integral'.

La película que voy a analizar ha sido escogida por una razón particular. Esta película es el resultado de la colaboración entre el etnólogo Lljubomir Reljić, la etnomusicóloga Svetlana Azanjac, el camarógrafo Branislav Kuzmanović y el director Slobodan Simojlović. Ellos han producido películas muy importantes y la mayoría de ellas representa un ejemplo excelente de una auténtica reconstrucción. Esta película confirma esto. Muestra una práctica ritual que se realizó durante siglos y en algunas partes de la película está presentada como reconstrucción.

El nombre de esta película es Vido, Vidovdane (producida por RTS TV Beograd, Serbia, 2002). La película muestra las costumbres de los habitantes de Timočka Krajina (al este de 
Serbia) relacionadas con Vidovdan (el día de San Vito) a través de la reconstrucción. La reconstrucción describe los orígenes y el desarrollo de estas costumbres desde el culto precristiano al antiguo dios eslavo de la luz y la guerra Svetovid hasta la celebración llamada slava (festividad serbia del santo patrono).

A lo largo del Cristianismo, Vidovdan ha sido identificado con el santo precristiano, y se ha convertido en la festividad dedicada principalmente a los caídos en la batalla de Kosovo y otras guerras en Serbia. Estas creencias han sido grabadas en el pueblo de Lenovac, cerca de Zaječar (al este de Serbia).

Tenemos que destacar una vez más que la línea divisoria entre documentos y reconstrucciones en la película etnográfica es puramente condicional y raras veces clara. Las reconstrucciones muchas veces están cargadas de demasiada documentación y comentarios orales. A lo mejor sería posible descubrir incluso algunas características regionales en lo que se refiere a esto.

Se puede notar que los autores influyen en la forma de la realidad que retratan ya que su simple presencia como forasteros (en cooperación con un pequeño o gran grupo de colaboradores y tecnología complicada) cambia el comportamiento de la gente en un ambiente que resulta desconocido para los autores. ${ }^{2}$

Las películas que serán descritas son unos ejemplos de la identificación urbana:

El nombre de la primera película es Lana, Nataša y Ksenija (Producida por VFC Zastava Film, Serbia, 2005). Un grupo de jóvenes entusiastas de Belgrado ha realizado el objetivo de luchar para proteger su propia tradición y cultura ante la urbanización global. Tres chicas jóvenes están tratando de retroceder el tiempo abandonando lo contemporáneo y volviendo a lo tradicional. Cambiando su estilo, llevando una vestimenta tradicional nacional, están describiendo la necesidad interior de regresar a sus raíces a pesar de las tendencias de globalización. La película se caracteriza por la estilización que representa un alejamiento de la realidad y las características de una tendencia impopular.

El nombre de la segunda película es Kalenić, los ultimos dias del mercado de la ciudad (dirigida por Ivan Vuković y Milan Miletić, Serbia, 2010).

El humor sutil y el enfoque nostálgico de esta película nos traen la historia sobre la cultura tradicional de los mercados al aire libre en Serbia. Tales mercados se están volviendo cada día más modernos, perdiendo el sentido original que tuvieron en la vida de la comunidad. Esta película muestra cuatro estaciones en la vida de un mercado de Belgrado, que vive sus últimos días dado que está modernizándose cada vez más. Esta película no sólo muestra el auténtico enfoque del autor sobre la realidad sino que también se ve muy influenciada por la antropología. Por esa razón podríamos destacar el criterio estético como uno de los más importantes en la evaluación de los valores de las películas que intentan reflejar la realidad de la vida a través de la gente y los eventos en su ambiente natural y socio-cultural.

Analizar estas películas nos ayuda a determinar diferentes modelos de eventos culturales contemporáneos en su forma deseada, lo que es necesario para entender cómo funcionan los cambios culturales. ${ }^{3}$

Las películas etnográficas en Serbia hoy no deberían tratar sólo de costumbres, bonitos paisajes, identidad étnica y música tradicional. Es necesario hacer nuevas películas etnográficas/antropológicas que deberían describir los asuntos que no han sido investigados. 
Es importante conservar la autenticidad y las características originales del documental, sobre todo si estamos tratando de usar esta perspectiva para orientar a los espectadores hacia la definición de la imagen de la identidad.

\section{Conclusión}

Se puede notar que hoy en día existen más películas que exploran los temas a un nivel fenomenológico, tratando de describir la situación real, sin idealización de la comunidad observada. La idealización del autor es también cada vez menos común, aunque todavía se puede notar en la reconstrucción de las costumbres. Esto pasa como consecuencia del trabajo realizado en los estudios etnográficos anteriores, cuando la investigación no lograba separar el nivel de modelo ideal del auténtico, afirma Lj. Gavrilović.

Las investigaciones dentro de la comunidad no han sido grabadas todavía aunque bien se sabe que si les explicamos a los miembros de una comunidad como grabar los eventos independientemente, sin la influencia de los etnólogos o cineastas, obtenemos una imagen diferente, una imagen de la cultura vista desde dentro (Gavrilović, 2004: 30,31).

Analizar estas películas nos puede ayudar a notar la intensidad de los cambios sociales después de la ruptura de Yugoslavia, y también gracias a estos análisis se puede seguir el avance de la globalización en la sociedad serbia.

En la era actual, con el advenimiento de la tecnología digital, tiene sentido hablar de una revolución más en la antropología visual, una revolución que todavía no ha sido comprendida, pero su alcance ya se puede notar en los programas de varios festivales, y sobre todo en el rápido desarrollo de los medios interactivos (Catálogo del decimoctavo Festival Internacional de la Película Etnológica, Belgrado, 2009).

Esto forma parte de la entrevista dedicada a la antropología visual con Peter Jan Crawford, realizada por Dr. Slobodan Naumović del departamento de etnología y antropología de la Facultad de filosofía de Belgrado. Los fragmentos de la entrevista están contenidos en el Catálogo del decimoctavo Festival Internacional de la Película Etnológica, Belgrado, 2009. Poco después de la aparición de nuevas tecnologías, los etnólogos y los antropólogos europeos e internacionales se concentraron en el significado visual y en la interpretación del fenómeno en varias culturas. Lo mismo ocurrió con la visualización del tema (como en el curso universitario) de la ciencia etnológica: aceptamos los dos aspectos de esa ciencia, al igual que nos hemos acostumbrado a la nueva tecnología, suponiendo que el desarrollo tecnológico nos pueda ayudar a superar su impacto negativo (Jones, 2001: 8).

La educación le convierte a un hombre común en un experto, o tal vez en un futuro cineasta. La educación en el campo de la cinematografía y los medios de comunicación visuales modernos puede ayudar en la expansión de la masa crítica de la gente que sabe 
cómo ver, analizar y evaluar los productos de la etnografía visual y discutir sobre los documentales como medio de comunicación relevante de la práctica social y cultural moderna y establecer diferencias entre ellos (Kriznar, 2007: 11).

Uno necesita tomar en cuenta la validez de la objetividad de la película etnológica/antropológica. En esta época de globalización, todos los desarrollos en el tiempo y el espacio necesitan ser documentados urgentemente y por eso, la repentina vuelta a la tradición requiere un buen enfoque crítico del material visual. Yo creo que la antropología visual obtendrá más importancia en la presentación de las identidades culturales en el futuro.

\section{Notas}

1. Este estudio se enmarca en el proyecto número 47016, financiado por el Ministerio de Educación y Ciencia de la República Serbia.

2. Es normal esperar que la película etnográfica lleve el peligro de mostrar las cosas en un espejo distorsionado; la vista subjetiva del autor y sus percepciones disminuyen la posibilidad de ser auténtico, y por tanto los espectadores reciben una imagen "adornada", irreal. 3. El famoso etnólogo serbio Dr. Dragoslav Antonijević, consideraba que los etnólogos podían evaluar la película etnográfica y la cultura representada. La grabación de la cultura tradicional se hará sistemáticamente y de una manera correcta solamente si los etnólogos realizan la grabación y colaboran profesional y pragmáticamente con los expertos en medios de comunicación.

\section{Referencias Bibliográficas}

Bauzinger, H. (2002). Etnologija. Belgrado: Biblioteka XX vek, 315-320.

Chiozzi, P. (1989). Reflexiones sobre la película etnográfica con la Bibliografía general ( Reflections on ethnographic film with a General bibliography). Visual anthropology vol. 2, no. 1. London, p. 56.

Drljača, D. (2003). Etnografski film - između dokumenta, rekonstrukcije i stilizacije. Dvanaesti međunarodni festival etnološkog filma, Katalog. Belgrado: Etnografski muzej.

Gavrilović, Lj. (2004). Balkanski kostim Nikole Arsenovića. Belgrado: SANU - Etnografski Institut, 52, 136. 155-156.

Jones, S. (2001). Виртуелна култура, Библиотека XX век. Belgrado, 6-170.

Jovanović, B. (2005). Umetnost vizuelne antroplogije. Belgrado: Međunarodni Festival Etno loškog Filma Katalog, 6-13.

Kriznar, N. (2007). Perspektive za edukaciju u vizuelnoj antropologiji. Šesnaestog međuna rodnog festivala etnološkog filma, Katalog. Belgrado: Etnografski muzej, 8-11.

Marjanović, V. (2002). Етнолошки филм у Етнографском музеју, Гласник Етнографског музеја 65-66. Belgrado.

Radojičić, D. (2010). Ethnological/Ethnographic film in Serbia. Bratislava: Slovensky narodo pis, vol. 5, No. 58, 628-635. 


\section{Bibliografía}

Antropología Visual: Recuperado el 05 de 2012: http://www.visualanthropology.net/

Bauzinger, H. (2002). Etnologija. Belgrado: Biblioteka XX vek, 315-320.

Chiozzi, P. (1989). Reflexiones sobre la película etnográfica con la Bibliografía general ( Reflections on ethnographic film with a General bibliography). Visual anthropology vol. 2, no. 1, London, p. 56.

Drljača, D. (2003). Etnografski film - između dokumenta, rekonstrukcije i stilizacije. Dvanaesti međunarodni festival etnološkog filma, Katalog. Belgrado: Etnografski muzej.

Etnografía Visual Participativa, Recuperado el 02 de 2012: http://www.slideshare.net/vin centobrien/participatory-visual-ethnography

Etnografía Visual - Teoría Actual, Recuperado el 04 de 2012 de Youtube: http://www.you tube.com/watch? $\mathrm{v}=\mathrm{gD}-\mathrm{Pjzz} 7 \mathrm{LfU}$.

Gavrilović, Lj. (2004). Balkanski kostim Nikole Arsenovića. Belgrado: SANU - Etnografski Institut, 52, 136. 155-156.

Kriznar, N. (2007). Perspektive za edukaciju u vizuelnoj antropologiji. Šesnaestog međuna rodnog festivala etnološkog filma, Katalog. Belgrado: Etnografski muzej, 8-11.

Jones, S. (2001). Виртуелна култура, Библиотека XX век. Belgrado, 6-170.

Jovanović, B. (2005). Umetnost vizuelne antroplogije. Belgrado: Međunarodni Festival Etno loškog Filma Katalog, 6-13.

Marjanović, V. (2002). Етнолошки филм у Етнографском музеју, Гласник Етнографског музеја 65-66. Belgrado.

Radojičić, D. (2010). Ethnological/Ethnographic film in Serbia. Bratislava: Slovensky narodo pis, vol. 5, No. 58, 628-635. 
Summary: The ethnographic film is a subtype of the documentary film. It deals with life and popular traditions, and can be used as an illustration, but also as a source of ethnographic and anthropological research. The ethnological film that is developed today in Serbia, can be used as a source for the study of cultural identification, but also as an instrument to establish cultural identity. Four local movies that gather traditional and modern will be analyzed at the level of material and spiritual subjects.

Key words: cultural identity - current progress status - ethnographic film - Ethnographic Film International Festival of Belgrade - Media.

Resumo: O filme etnográfico representa um subtipo de filme documental, um que trata da vida e das tradições populares, que pode ser usado como ilustração, mas também como fonte da pesquisa etnográfica e antropológica. O filme etnológico, assim como se faz hoje em Sérvia, pode ser utilizado como fonte para o estudo da identificação cultural, mas também como instrumento para estabelecer a identidade cultural. Quatro filmes domésticos que unem o tradicional e o moderno serão analisadas ao nível da temática material e espiritual.

Palavras chave: estado de situação atual - Festival Internacional do filme etnográfico em Belgrado - filme etnográfico - identidade cultural - meios de comunicação. 